\title{
A BIM-DATABASE-INTEGRATED SYSTEM FOR CONSTRUCTION COST ESTIMATION
}

\author{
Hang Thu Thi Le ${ }^{1}$, Veerasak Likhitruangsilp ${ }^{2 *}$, and Nobuyoshi Yabuki ${ }^{3}$ \\ ${ }^{1}$ Department of Civil Engineering, Faculty of Engineering, Chulalongkorn University, Bangkok, Thailand \\ Tel. +669 5010 3108, e-mail: hang.ththle@ gmail.com \\ ${ }^{2}$ Department of Civil Engineering, Faculty of Engineering, Chulalongkorn University, Bangkok, Thailand \\ Tel.+662 218 6460, e-mail: Veerasak.L@ chula.ac.th \\ ${ }^{3}$ Division of Sustainable Energy and Environmental Engineering, Graduate School of Engineering, Osaka \\ University, Osaka, Japan, e-mail:yabuki@see.eng.osaka-u.ac.jp
}

Received Date: March 28, 2020; Revised Date: July 3, 2020; Acceptance Date: October 5, 2020

\begin{abstract}
This paper presents a building information modeling (BIM)-database-integrated system for estimating the construction costs of building projects. The proposed system consists of four main modules: (1) the relational database management module, (2) the visualized BIM-integrated module, (3) the cost estimation module, and (4) the BIM-integrated report module. The relational database management module is designed to store and update the necessary data, which are extracted from BIM models. The visualized BIM-integrated module assists users in visualizing the complex building elements while performing cost estimating. The cost estimation module computes construction cost components. It can also automatically adjust to the change of the building element parameters while estimating costs. This module can minimize human errors associated with manual data input and calculation. The BIMintegrated report module allows users to access and comprehend the results conveniently. As compared to traditional 2D CAD drawings, the proposed system offers a more efficient methodology for construction cost estimating through $3 \mathrm{D}$ models. It can also minimize time, costs, and errors in the cost estimating process for building procurement.
\end{abstract}

Keywords: 5D BIM, Construction cost estimation, Building Information Modeling (BIM), Building procurement, Relational database management, Visual programming

\section{Introduction}

Cost estimating is a crucial step in the procurement process of construction projects [1]. It encompasses collecting and analyzing necessary data for determining the cost parameters of a construction project [2]. The accuracy of estimated costs, which is an essential factor for the success of projects, depends on many factors such as estimators' experience, the quality of data, and the amount of time available for preparing bid proposals [3, 4]. Conventional construction cost estimating is primarily based on 2D drawings and is usually carried out by manual calculations or spreadsheets. It is a time-consuming process, which requires a large amount of data and repetitive calculations [5].

Building information modeling (BIM) is a modern process that is increasingly adopted in the construction industry worldwide. BIM has been mandated for certain construction projects in several countries such as Finland, USA, Denmark, South Korea, Netherlands, Japan, China, Hong Kong, Australia, Canada, Dubai, Singapore, New Zealand, United Kingdom, Norway, Sweden, Switzerland, Russia, Mexico, France, Scotland, Qatar, 
Portugal, Spain, Germany, and Italy $[5,6,7,8]$. This is because BIM can minimize design and construction errors and omissions, support the collaboration among all project participants, reduce repetitive works, facilitate cost control, and promote business for the architecture, engineering, and construction (AEC) industry [9, 10]. The number of construction projects adopted BIM in the US was only 28 percent in 2007, reached 71 percent in 2012, and continued to grow since then [11]. BIM offers various benefits for construction management, including project cost estimating. Yet, cost estimating by BIM must encounter various challenges. For example, the cost database and unit of measurement are usually based on traditional standards, which are not compatible with BIM objects [12]. The data structure of a BIM model is inappropriate for the elements required by classification structures [13]. Current BIM tools cannot efficiently manage all necessary cost data [14]. The completeness and correctness of a BIM model significantly contribute to the accuracy of estimated quantities $[15,16]$. Since the data extraction is often performed manually, it is extremely time-consuming and yields incorrect and inconsistent results [17, 18]. Visual programming has been greatly advanced in recent years. It can extend the cost estimating capacity of BIM authoring programs (e.g., Autodesk Revit) by integrating a graphical algorithm with BIM software.

In this paper, we develop a BIM-database-integrated system for estimating the construction costs of building projects. The proposed system can address the limitations of conventional construction cost estimating by integrating a database and visual programming with a BIM authoring program. The system consists of four main modules: (1) the relational database management module, (2) the visualized BIM-integrated module, (3) the cost estimation module, and (4) the BIM-integrated report module. In addition to performing automated cost estimating, the system allows users to visualize the cost estimating process, which enhances the productivity of quantity takeoff and cost calculation in building procurement. It also facilitates the communication of the results among all project stakeholders. This system, therefore, provides a new methodology to organize and manage cost estimating data by integrating a database management system, a BIM authoring program, a spreadsheet system, and visual programming.

\section{BIM for Construction Cost Estimating}

BIM is defined as a digital technology that represents the functional and physical characteristics of a construction product (e.g., a building) through the creation of 3D virtual models, which can increase the quality and efficiency of construction activities [19]. BIM is acknowledged as a supporting technology to reduce waste, increase the productivity of construction works, and support a sustainable environment. Many countries have mandated BIM as an essential requirement in their construction projects. The UK government has mandated that the public projects with the initial capital cost over 5 million GBP use BIM level 2 by 2016 [20]. Norway, Denmark, Netherlands, and Finland have also instructed their public projects to use BIM for promoting sustainable growth [21].

The merits of construction cost management can be enhanced by adopting BIM technology to process project cost data and information [22]. BIM can create 3D virtual models from the ideas of designers, which support collaboration and communication among all project stakeholders. BIM models can reduce re-estimating time and cost when 
construction changes occur during the design and construction phases. BIM can also enhance the accuracy of quantity takeoff as compared with manual calculations [14, 15, 22, 23].

Various research works on BIM has been carried out, including 5D BIM. The Royal Institution of Chartered Surveyors (RISC) and the Hong Kong Architectural Services Department proposed the use of surface area characteristics to measure the number of building elements such as walls, floors, windows, doors, and roofs of BIM projects [23, 24, 25]. The National Institute of Building Sciences (NIBS), the United States Army Corps of Engineers, the General Services Administration (GSA), the Association for the Advancement of Cost Engineering International (AACE), and the American Society of Professional Estimators (ASPE) collaborated on developing a system for estimating costs throughout the project life-cycle [26]. A BIM-based framework for performing detailed cost estimating of construction projects was proposed by integrating a BIM product model with a construction process model, which is retrieved from RSMeans [27]. A BIM-based application was developed for estimating the costs of the tendering process of building projects in China. It is a semi-automatic system, which is based on the use of the design model through the Industry Foundation Classes (IFC) standard [28]. The integrated system of BIM and database management was a semiautomatic approach for 6D life-cycle cost estimating of building projects [29]. A BIMenabled system for building life-cycle cost analysis was developed by integrating Autodesk Revit, Dynamo, Microsoft Excel, and Microsoft Access [30]. It should be noted that most of the current BIM tools can support the quantity takeoff of a single-element model only. In addition, they cannot manipulate all the necessary data to carry out construction cost estimating.

A number of commercial BIM-based software has been developed for estimating construction costs from design models such as CostX [31], Innovaya Visual Estimating [32], and Vico Estimator [33]. However, most of them are based on the required standards, which cannot be readily modified by users. They do not actually perform 5D cost estimating directly on BIM models [27]. With the data loss while importing them, the results provided by the commercial software may have low reliability. We also have to significantly invest in acquiring and maintaining the computer software. Thus, it is necessary to introduce a new 5D BIM-based system that can address the aforementioned challenges.

\section{Research Methodology}

Figure 1 displays the research methodology to develop the proposed system, which consists of six main steps. The first step is reviewing relevant literature to identify critical problems, research gaps, and applications of BIM for construction cost estimating. The second step is establishing the conceptual framework of the proposed system. In the third step, we examine all potential software based on the system requirements and attributes of each software. The fourth step is developing the system by outlining the system architecture and the details of the four modules of the system. The fifth step encompasses processing the necessary data and information, which consists of two main tasks: data collection and data organization. Finally, the system is applied to an actual building project for evaluating its efficacy and practicality. The system results will be compared with the results from manual calculations to verify the reliability of the system. 


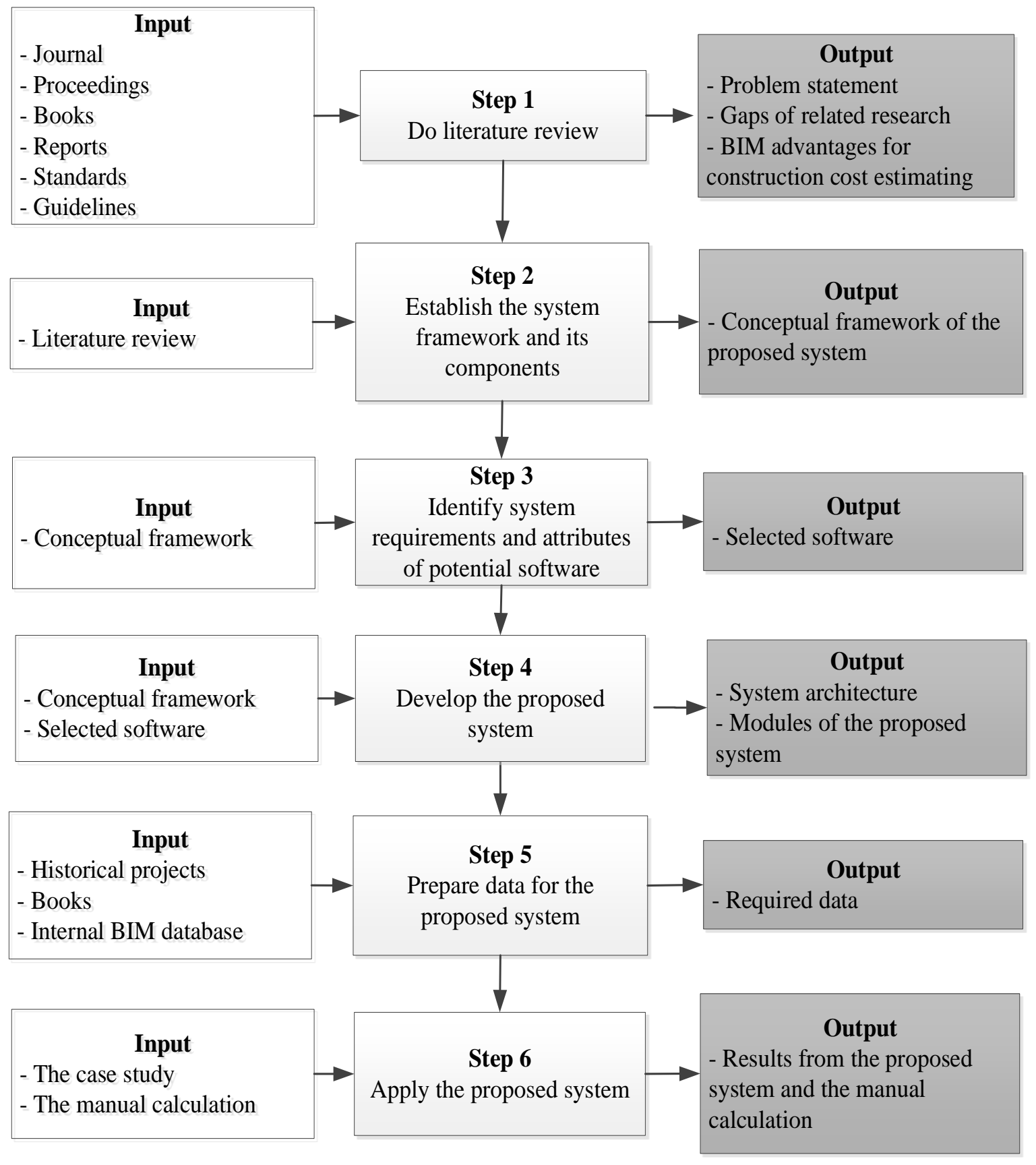

Figure 1. Six steps of the research methodology

\section{System Architecture}

The system architecture illustrates the requirements of each system module, the relation of the modules, and the communications among the selected software [35]. In this paper, the system architecture design entails 13 steps, as shown in Figure 2. First, we design the structure of a database management system. The necessary data are collected from two main sources, namely, past projects and the RSMean data. The data are analyzed and arranged in accordance with the UniFormat standard. The data are then input into the database tables and transferred to a spreadsheet system. In Step 5, a conceptual BIM model is created by BIM authoring software, namely, Autodesk Revit. Because BIM models cannot and should not contain all data that are necessary for construction cost estimating, we adopt structured query language (SQL) for linking such data between the 
relational database and the conceptual BIM model. This can be achieved by exporting the queried data to a spreadsheet file, which is subsequently integrated with the BIM model. Once the complete BIM model has been derived, it can be used for construction cost estimating. In Step 9, the spreadsheet report is developed to store the results of the proposed system. All building element types of the complete BIM model are selected, and the necessary data are extracted from the model. The construction costs of the project are automatically computed by a graphical algorithm. The results from the system are exported to the spreadsheet report automatically. Figure 2 illustrates the various platforms and the system modules as well as summarizes the detailed steps entailed in each system module.

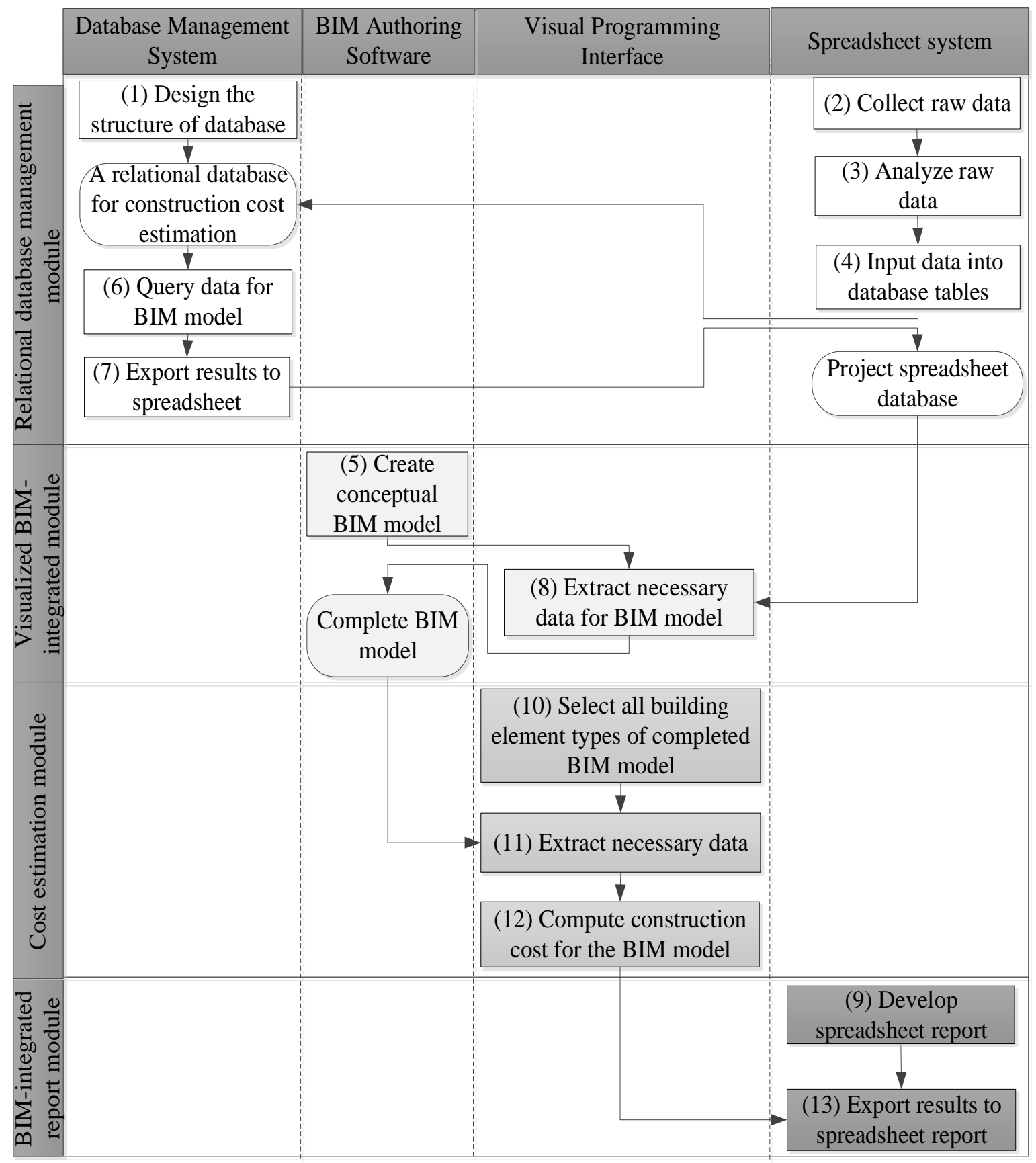

Figure 2. System architecture 


\section{Relational Database Management Module}

A relational database system is developed as a data warehouse for the proposed system due to its simplicity and efficiency for querying data. The main function of this system module is to provide necessary data for the BIM model. These data conform to the UniFormat standard, which is chosen for classifying the building elements of the BIM model. Figure 3 shows the five steps for developing the relational database management module. First, we identify an appropriate type of database and data format for estimating construction costs. The next step is to define the structure of database tables and their relations. Then, we collect raw data from various data sources. These data are then analyzed and organized per the UniFormat standard. Finally, the data are input in the database tables.

In this module, four parameters must be recorded in the database tables for each building element type of the BIM model, namely, element type code, description, unit, and construction unit rate. The raw data entail material, labor, and equipment unit costs, which are applied to the project. In this paper, these data are gathered from two main sources. The first source is historical data of similar past projects. If they are not available, the data will be obtained from "Assemblies Cost with RSMeans Data 2018, $43^{\text {rd }}$ Annual Edition" book [36]. The data are prepared in a spreadsheet (herein Microsoft Excel) and input in the relational database tables. Table 1 displays an example list of different exterior window types, which contain the element type code, description, quantity per unit, unit, area per unit, material unit cost, cost per unit, and cost per area of each exterior window type.

Figure 4 illustrates the structure of the relational database of the proposed system. Eight tables are created to store the necessary data for the BIM model, namely, ExteriorWall, ExteriorWindow, Floor, Roof, InteriorWall, InteriorWindow, Door, and Assembly. As can be seen, each table contains five fields: ElementTypeCode, Description, Unit, ConstructionUnitRate, and AssemblyCode, except for the Assembly table, which contains only two fields, namely AssemblyCode and Description. The ElementTypeCode field contains a unique code that identifies a building element type. The Description field illustrates the name of each building element type. The Unit field stores the calculated unit for each building element type such as the square meter of the door area. The ConstructionUnitRate field is associated with the construction unit cost of each building element type. The AssemblyCode field encompasses the building structural classification to which a building element type belongs. This classification is based on Level 3 of the UniFormat classification system for the building structural classification. The one-to-many relation is adopted for connecting the tables of this relational database. The ElementTypeCode is a primary key of these tables, which links the two interrelated database tables.

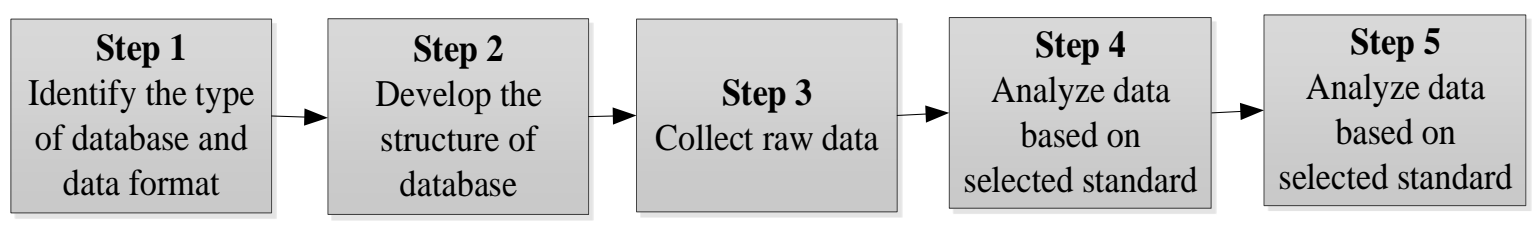

Figure 3. Steps for developing the relational database management module 
Table 1. Example List of Different Exterior Window Types

\begin{tabular}{|c|c|c|c|c|c|c|c|c|}
\hline \multirow[b]{2}{*}{$\begin{array}{c}\text { Element } \\
\text { Type Code }\end{array}$} & \multirow[b]{2}{*}{ Description } & \multirow[b]{2}{*}{ Quantity } & \multirow[b]{2}{*}{ Unit } & \multirow[b]{2}{*}{$\begin{array}{c}\text { Area } \\
(\mathrm{SQM})\end{array}$} & \multicolumn{4}{|c|}{ Construction } \\
\hline & & & & & $\begin{array}{c}\text { Material } \\
\text { Unit Cost } \\
\text { (Baht) }\end{array}$ & $\begin{array}{c}\text { Labor } \\
\text { Unit Cost } \\
\text { (Baht) }\end{array}$ & $\begin{array}{c}\text { Cost } \\
\text { Per Unit }\end{array}$ & $\begin{array}{c}\text { Cost Per } \\
\text { Area }\end{array}$ \\
\hline B2020111 & Exterior metal-glazed window W1' & 1 & SET & 7.41 & 11,115 & 5,928 & 17,043 & 2,300 \\
\hline B2020112 & Exterior metal-glazed window W1" & 1 & SET & 3.71 & 5,558 & 2,964 & 8,522 & 2,300 \\
\hline B2020113 & Exterior metal-glazed window W1"” & 1 & SET & 3.71 & 11,115 & 5,928 & 17,043 & 4,600 \\
\hline B2020114 & Exterior metal-glazed window W1" " & 1 & SET & 7.41 & 11,115 & 5,928 & 17,043 & 2,300 \\
\hline B2020115 & Exterior metal-glazed window W1",", & 1 & SET & 7.41 & 11,115 & 5,928 & 17,043 & 2,300 \\
\hline B2020211 & Exterior frosted glazed window W2 & 1 & SET & 5.46 & 18,900 & 8,100 & 27,000 & 4,947 \\
\hline B2020311 & Exterior glazed window W2' & 1 & SET & 4.28 & 14,814 & 6,349 & 21,163 & 4,948 \\
\hline B2020312 & Exterior glazed window W3 & 1 & SET & 3.07 & 9,450 & 4,050 & 13,500 & 4,399 \\
\hline B2020313 & Exterior glazed window W3' & 1 & SET & 2.39 & 7,367 & 3,157 & 10,524 & 4,399 \\
\hline B2020116 & Exterior metal-glazed window W4' & 1 & SET & 11.21 & 16,815 & 11,210 & 28,025 & 2,500 \\
\hline B2020117 & Exterior metal-glazed window W4" & 1 & SET & 5.61 & 8,408 & 5,605 & 14,013 & 2,500 \\
\hline B2020118 & Exterior metal-glazed window W4"” & 1 & SET & 10.03 & 15,045 & 10,030 & 25,075 & 2,500 \\
\hline B2020121 & Exterior metal-glazed window W5 & 1 & SET & 12.54 & 18,810 & 12,540 & 31,350 & 2,500 \\
\hline B2020122 & Exterior metal-glazed window W5" & 1 & SET & 6.27 & 9,405 & 6,270 & 15,675 & 2,500 \\
\hline B2020511 & Exterior metal window W10 & 1 & SET & 1.00 & 1,500 & 1,000 & 2,500 & 2,500 \\
\hline
\end{tabular}

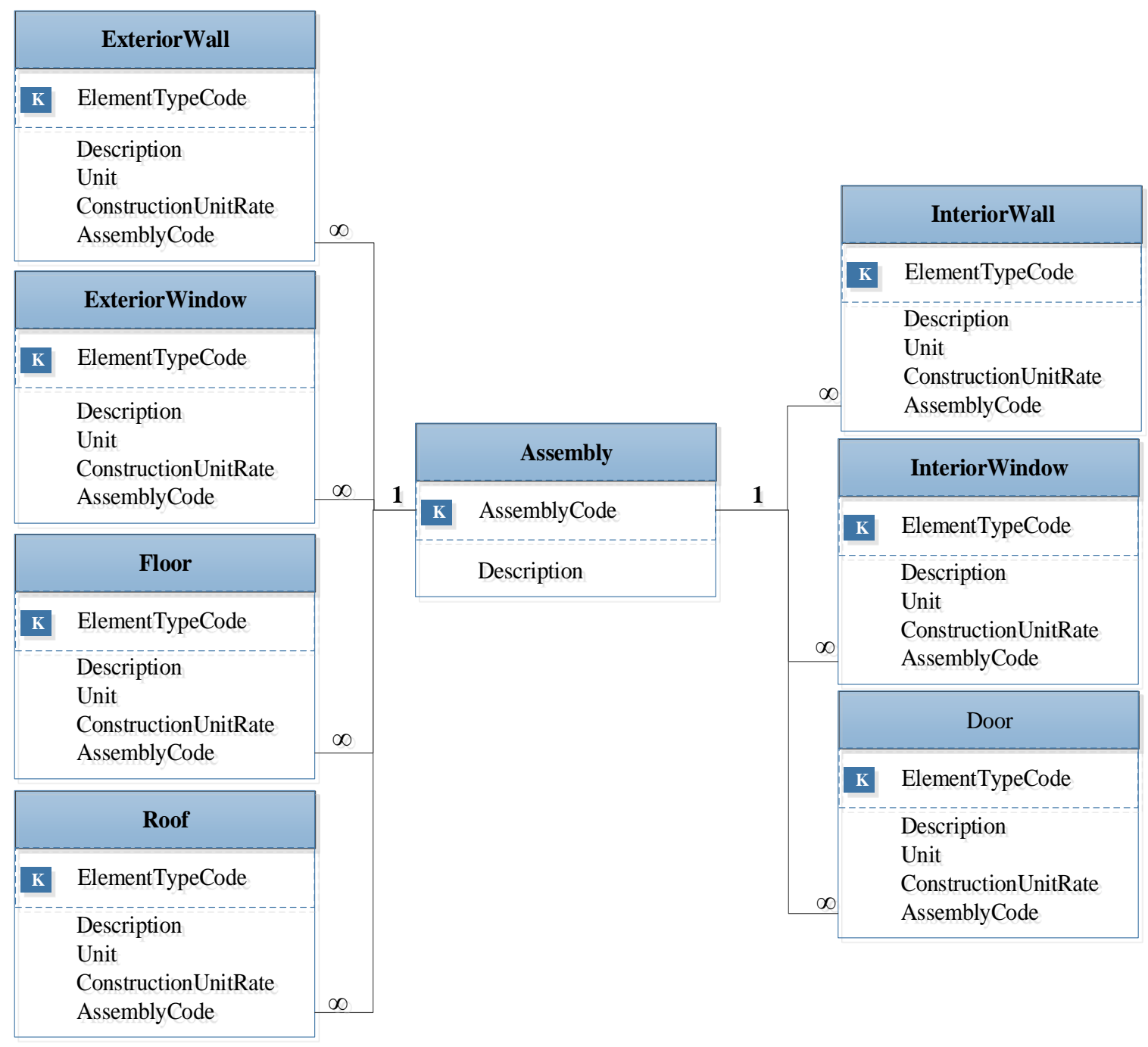

Figure 4. Structure of the relational database 


\section{Visualized BIM-Integrated Module}

The second system component is the visualized BIM-integrated module. It embraces visualization, which is an outstanding attribute of BIM models, for estimating construction costs. Designing this module concerns two main issues: the level of development (LOD) and the necessary data for construction cost estimating. The workflow for developing this module consists of six steps. The first step is to identify an appropriate LOD of building elements. A conceptual BIM model is created by the chosen authoring software. We then identify the data that are necessary for estimating the costs of each building element. The conceptual BIM model and the relational database are integrated with the visual programming interface. The last step is to extract the necessary data for characterizing the building element properties.

Since current BIM software cannot comprehensively accommodate all necessary data for cost estimating (i.e., 5D BIM), it is necessary to introduce additional attributes in BIM models to represent the properties of each building element. Yet, a BIM model usually contains a large number of building elements, the data of which are too voluminous to input manually. In this paper, an automated system is developed to extract the necessary data of all building elements of the BIM model to perform construction cost estimating. The system integrates a database management system, BIM authoring software, a visual programming interface, and a spreadsheet. First, the necessary data of all building element types in the conceptual BIM model are queried by using SQL and are provided in the form of a data set file. The queried data set is exported to a spreadsheet (Microsoft Excel). The necessary data in the spreadsheet are then extracted for the BIM model using the visual programming interface. This entire process is performed through visual scripts. The outcome of the visualized BIM-integrated module is the complete BIM model, in which each element contains both graphical and non-graphical data for construction cost estimating. The graphical data of an element include the length, height, thickness, and type of material of the element. The non-graphical data of an element entail the element type code and construction unit rate of that element model, as shown in Figure 5.

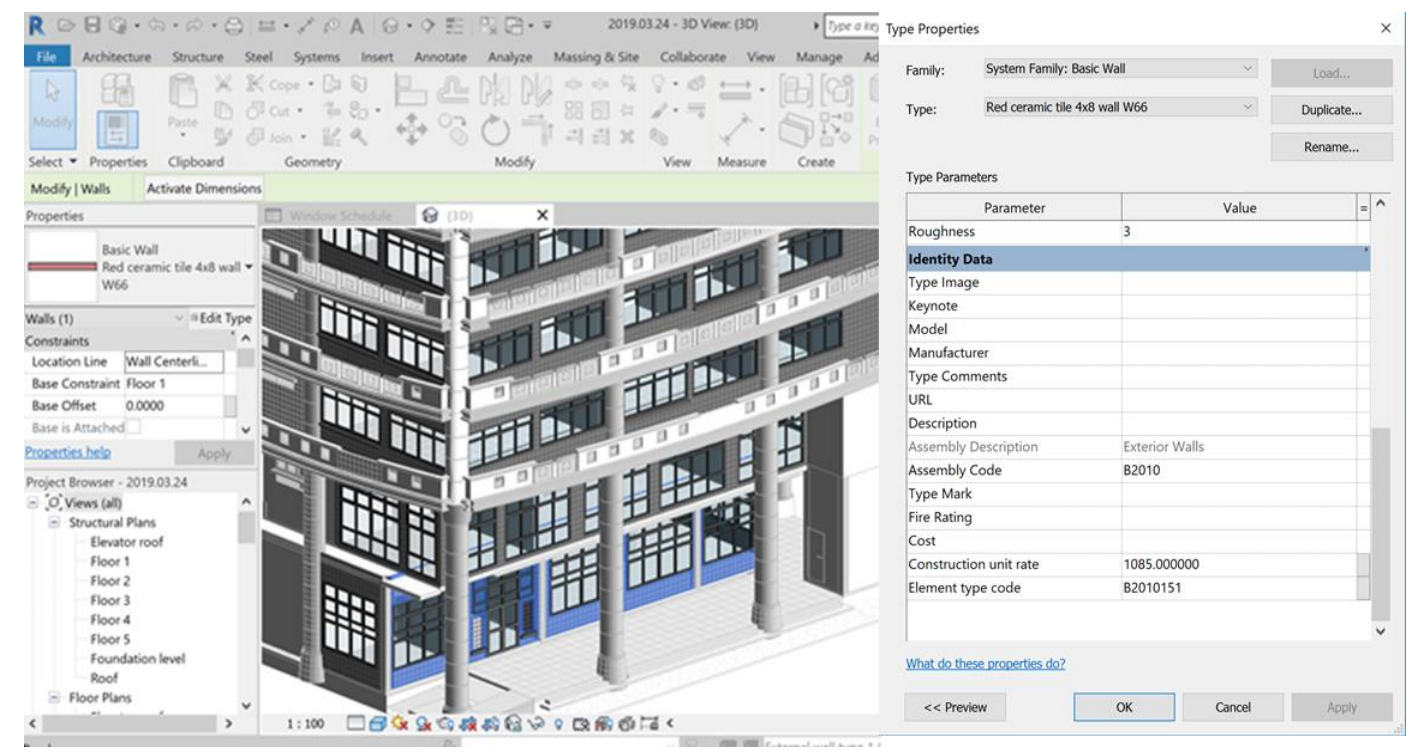

Figure 5. A wall type of the complete BIM model 


\section{Cost Estimation Module}

Developing the cost estimation module consists of two main parts. The first part is integrating the BIM model with the visual environment. The second part is defining mathematical models for estimating construction costs. Figure 6 displays an automatic quantity takeoff of a building element type, which consists of five steps. First, a building element is selected (herein wall). The module gathers all types of the selected element by using the GetAllElementsOfTypes node, which is written by Python programming language. The third step is calling the area parameter for collecting its value. The fourth step is obtaining the area of each element that belongs to the selected type. Finally, the module sums the areas of all elements of the selected type.

\section{BIM-Integrated Report Module}

Extracting and reporting the analytical results from BIM software and models are another challenge for several BIM users, especially those who are not familiar with the program. The BIM-integrated report module is designed to facilitate such processes. The module can access and extract the results from the cost estimation module by using the visual programming interface. It is developed by integrating the visual programming interface with a spreadsheet. A spreadsheet workbook is created for storing the results, which are transferred from the cost estimation module using visual scripts.

\section{Application Example}

To illustrate and verify the efficacy and practicality of the proposed system, it is applied to an actual building to perform detailed cost estimating of the architectural works. The building houses the Department of Civil Engineering, Faculty of Engineering, Chulalongkorn University, located in Bangkok, Thailand. Its architectural and structural details are typical for academic buildings in Thailand. Figure 7 displays the 3D BIM model of this building.

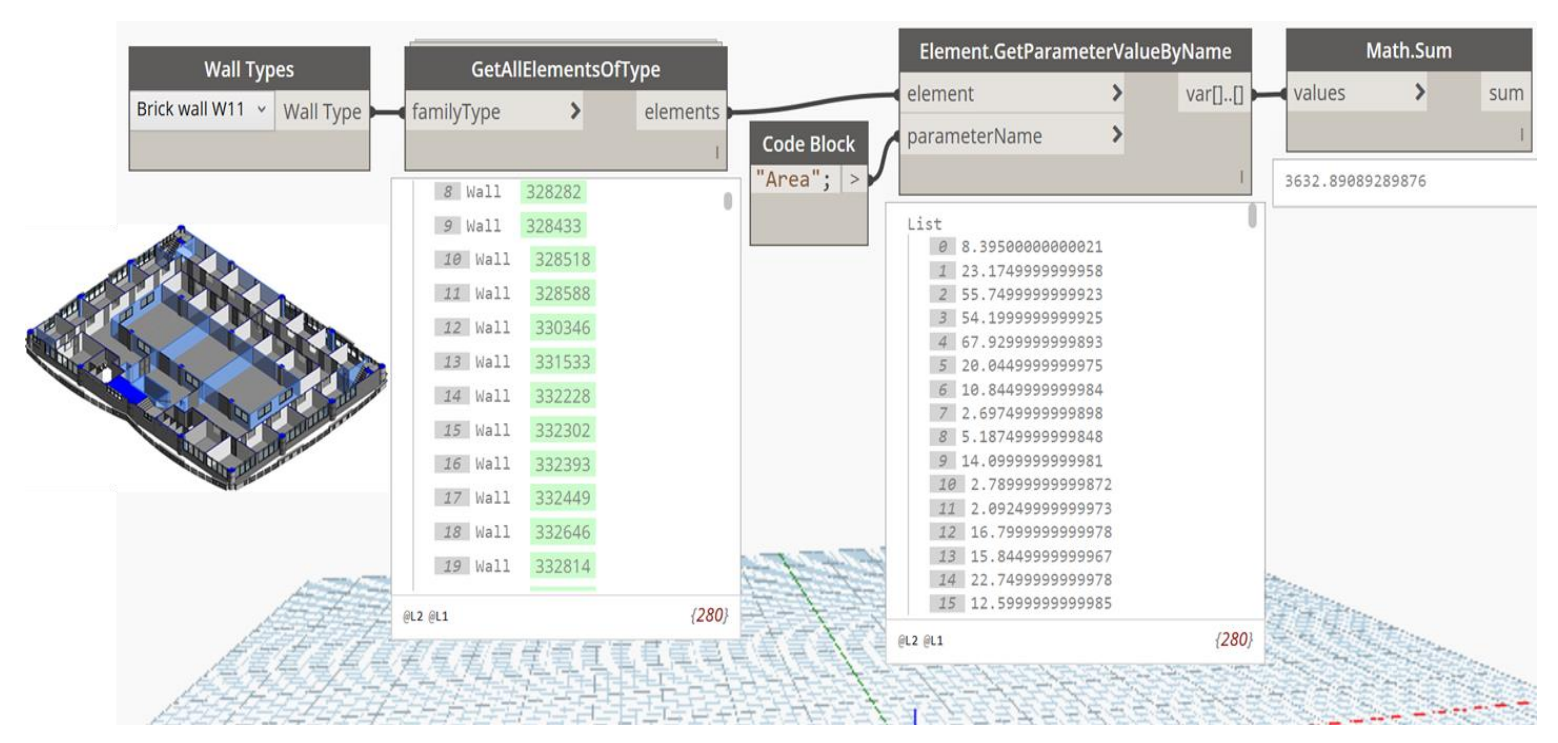

Figure 6. Workflow of the quantity takeoff process of a wall type 


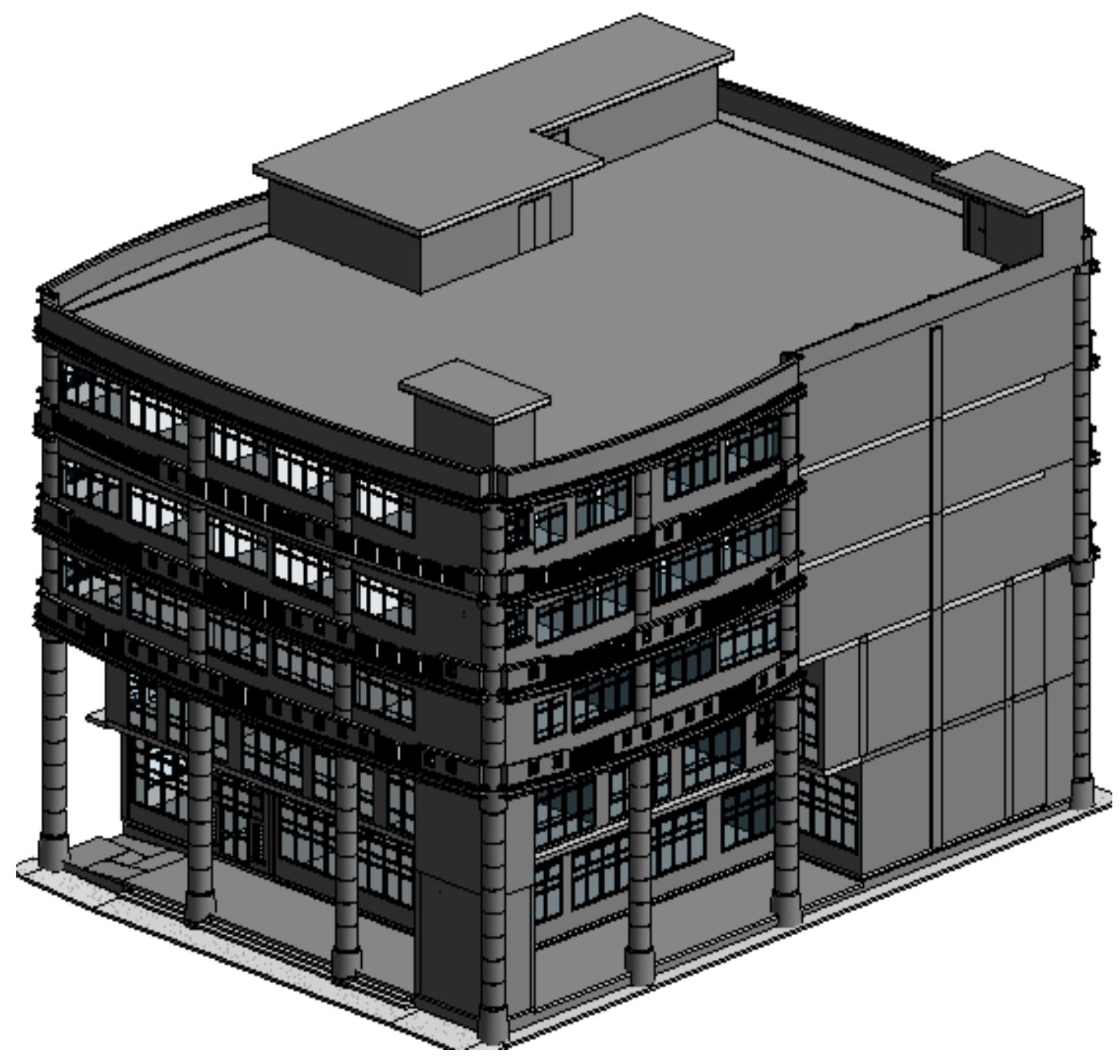

Figure 7. 3D BIM model of the application example

The workflow of the system application is as follows. First, a conceptual BIM model of the building was created by using Autodesk Revit. Since this BIM model cannot contain all necessary data for construction cost estimating, a database system was established to support cost estimating. The necessary cost estimating data for all building element types of the BIM model were queried from the relational database management module using SQL and Microsoft Access. The queried data were then exported to Microsoft Excel using a direct add-in link between Microsoft Access and Microsoft Excel. The output was a project spreadsheet file of the BIM model. Next, we integrated the spreadsheet data file with the conceptual BIM model using Dynamo scripts. The output was a complete BIM model for construction cost estimating. This complete BIM model was then combined with the visual environment for creating the cost estimation module. The mathematical models for construction cost estimating were computed to determine the construction costs of all building elements in the BIM model. The system results were exported to the spreadsheet workbook for reporting. Figure 8 depicts the workflow of applying the proposed system to the project example by using all platforms. 


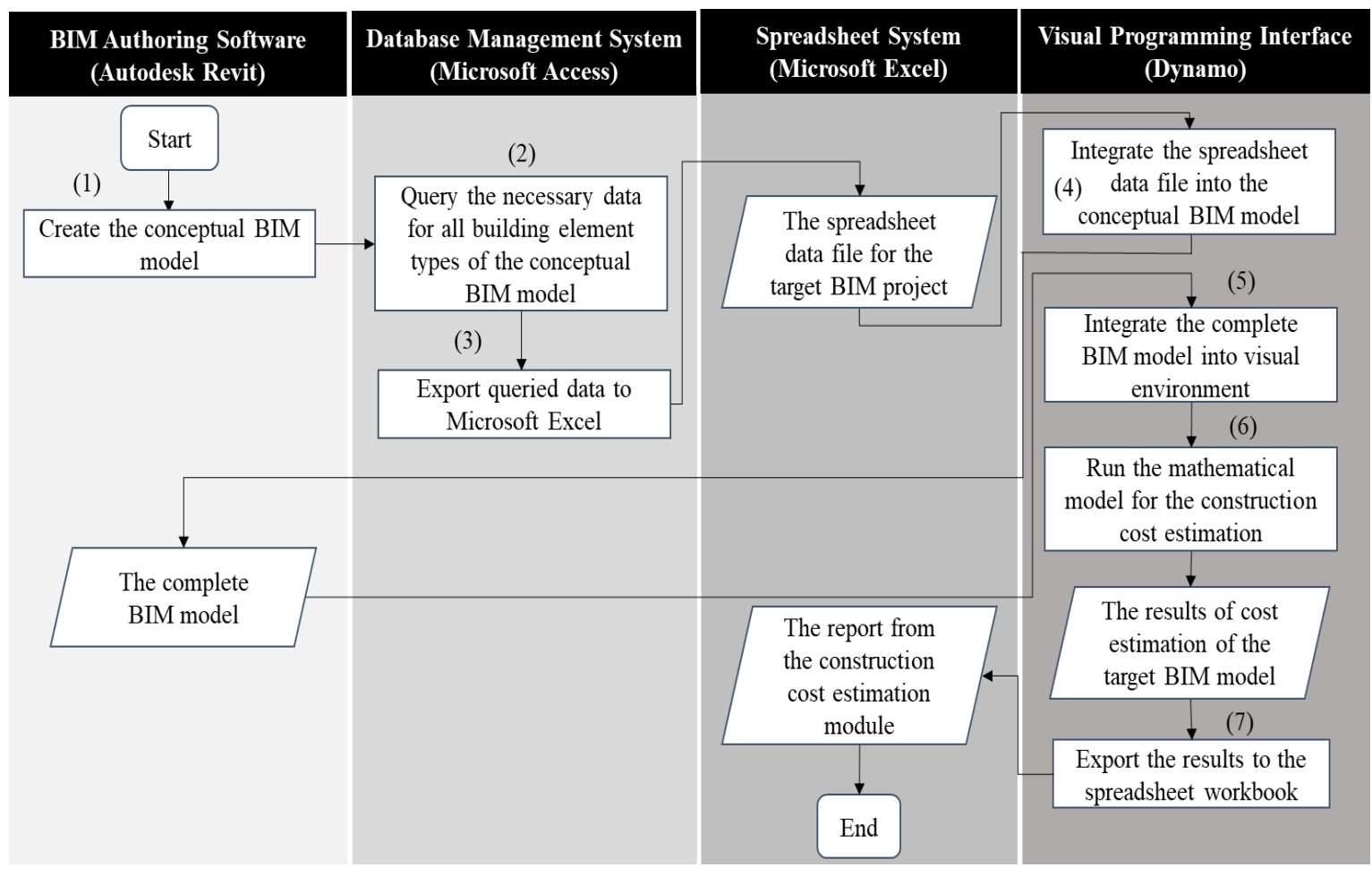

Figure 8. Workflow for applying the proposed system

\section{Result and Discussion}

Table 2 presents the estimated costs computed by the proposed system. The BIM model of this building consists of 44 element types with more than 1,000 element models. For example, there are 14 exterior window types such as exterior metal-glazed window W1', exterior metal-glazed window W1", and exterior metal-glazed window W1"'. Three interior window types are interior glazed window W7, interior glazed window W7', and interior glazed window W8. There are eight door types such as exterior metal-glazed double door D1, interior metal-glazed double door D2, and interior metal-glazed single door D3. Four exterior wall types are red ceramic tile $4 \times 8$ wall W66, cladding tile $12 \times 12$ and red ceramic tile $4 \times 8$ wall W36, brick and red ceramic tile $4 \times 8$ wall W16, and balcony wall W8-1. Four interior wall types are brick wall W11, gypsum wall W55, cladding tile $12 \times 12$ wall W3, and brick and cladding tile $12 \times 12$ wall W13. There are eight floor types such as gray stone floor F1, gray tile floor F2, ceramic tile floor F3, and white-gray terrazzo floor F5.

As can be seen, the report shows the four parameters for each building element type: the UniFormat code, the element name, the construction cost, and the percentage of construction cost. The total cost of the architectural works of this building is 24,960,040.38 Thai Baht. To evaluate the reliability of the results from the proposed system, we performed a manual calculation for an interior wall type of the case study building, namely, a brick wall W11. This wall type consists of 280 elements, which are located at different floors. The parameters of the building example in the manual calculation and the proposed system are the same. After comparing the results from both approaches, we found that they are similar. Thus, it can be concluded that the proposed system yields reliable results and can be used in practice. Detailed discussions of the proposed system can also be found in [37, 38]. 
Table 2. Results of the Project Example

\begin{tabular}{|c|c|c|c|}
\hline $\begin{array}{c}\text { Element } \\
\text { Type Code }\end{array}$ & Element Name & Construction Cost & Percentage \\
\hline$(1)$ & (2) & (3) & (4) \\
\hline B2020111 & Exterior metal-glazed window W1' & $971,783.35$ & 3.89 \\
\hline B2020112 & Exterior metal-glazed window W1" & $98,679.20$ & 0.40 \\
\hline B2020113 & Exterior metal-glazed window W1"' & $125,759.40$ & 0.50 \\
\hline B2020114 & Exterior metal-glazed window W1"'" & $70,445.55$ & 0.28 \\
\hline B2010151 & Exterior metal-glazed window W4' & $251,272.98$ & 1.01 \\
\hline B2010153 & Exterior metal-glazed window W4" & $12,179.27$ & 0.05 \\
\hline B2020118 & Exterior metal-glazed window W4"' & $37,545.00$ & 0.15 \\
\hline B2020121 & Exterior metal-glazed window W5' & $587,210.00$ & 2.35 \\
\hline B2020121 & Exterior metal-glazed window W5" & $114,750.00$ & 0.46 \\
\hline B2020211 & Exterior frosted glazed window W2 & $812,641.83$ & 3.26 \\
\hline B2020311 & Exterior glazed window W2' & $125,365.00$ & 0.50 \\
\hline B2020312 & Exterior glazed window W3 & $161,478.49$ & 0.65 \\
\hline B2020313 & Exterior glazed window W3' & $98,900.52$ & 0.40 \\
\hline B2020511 & Exterior metal window W10 & $3,517.50$ & 0.01 \\
\hline C1010711 & Interior glazed window W7 & $163,990.00$ & 0.66 \\
\hline C1010712 & Interior glazed window W7' & $7,680.00$ & 0.03 \\
\hline C1010713 & Interior glazed window W8 & $144,628.75$ & 0.58 \\
\hline B2030121 & Exterior metal-glazed double door D1 & $117,759.32$ & 0.47 \\
\hline B2030122 & Exterior metal single door D4 & $444,704.72$ & 1.78 \\
\hline B2030131 & Exterior plywood double door D9 & $200,103.16$ & 0.80 \\
\hline C1020111 & Interior metal-glazed double door D2 & $1,045,386.17$ & 4.19 \\
\hline C1020112 & Interior metal-glazed single door D3 & $1,544,487.84$ & 6.19 \\
\hline C1020113 & Interior metal-glazed double door D10 & $1,529,995.67$ & 6.13 \\
\hline C1020121 & Interior wood signle door D5 & $236,127.35$ & 0.95 \\
\hline C1020122 & Interior wood single door D7 & $17,258.58$ & 0.07 \\
\hline B2010151 & Red ceramic tile $4 \times 8$ wall W66 & $1,405,538.29$ & 5.63 \\
\hline B2010153 & Cladding tile $12 \times 12$ and red ceramic tile $4 \times 8$ wall W36 & $144,423.62$ & 0.58 \\
\hline B2010154 & Brick and red ceramic tile $4 \times 8$ wall W16 & $160,691.76$ & 0.64 \\
\hline B2010511 & Balcony wall W8-1 & $132,209.67$ & 0.53 \\
\hline C1010111 & Brick wall W11 & $1,889,103.26$ & 7.57 \\
\hline C1010151 & Gypsum wall W55 & $596,859.45$ & 2.39 \\
\hline C1010131 & Cladding tile $12 \mathrm{X} 12$ wall $\mathrm{W} 3$ & $4,250.00$ & 0.02 \\
\hline C1010211 & Brick and cladding tile $12 \mathrm{X} 12$ wall $\mathrm{W} 13$ & $417,511.09$ & 1.67 \\
\hline C3020411 & Gray stone floor F1 & $334,439.84$ & 1.34 \\
\hline C3020431 & Gray tile floor F2 & $841,886.60$ & 3.37 \\
\hline C3020441 & Ceramic tile floor F3 & $230,554.44$ & 0.92 \\
\hline C3020461 & White-gray terrazzo floor F5 & $23,917.50$ & 0.10 \\
\hline C3020471 & Concrete floor F6 & $136,484.79$ & 0.55 \\
\hline C3020432 & Gray tile floor F' & $5,373,555.79$ & 21.53 \\
\hline C3020412 & Gray stone floor F1' & $1,802,088.11$ & 7.22 \\
\hline C3020472 & Concrete floor F6' & $645,785.74$ & 2.59 \\
\hline C3020452 & Concrete roof with waterproofing F4 & $1,534,313.08$ & 6.15 \\
\hline C3020431 & Gray tile roof F2' & $111,477.84$ & 0.45 \\
\hline \multirow{2}{*}{\multicolumn{2}{|c|}{ Cometele toor ro }} & $251,299.86$ & 1.01 \\
\hline & & $24,960,040.38$ & 100.00 \\
\hline
\end{tabular}




\section{Conclusions}

This paper presents the BIM-database-integrated system for construction cost estimation. The system consists of four main modules: (1) the relational database management module, (2) the visualized BIM-integrated module, (3) the cost estimation module, and (4) the BIMintegrated report module. It is a new methodology to estimate project costs through a visualized 3D model. This visual model provides an efficient communication means of the estimates to all project stakeholders.

The BIM models of building projects usually contain a large number of element models, which take a significant amount of time for inputting the data and calculating the costs. Our system provides a systematic procedure to compile, organize, and store the necessary data to perform detailed cost estimating. It also offers an automated method to extract the necessary data from the BIM model for estimating costs by integrating BIM authoring software, a database management system, a spreadsheet, and the visual programming interface. Typical BIM models cannot comprehensively perform detailed cost estimating of building projects. The proposed system is designed to automatically take off the quantity and computing the costs of each building element type by using Dynamo and Python programming language. This workflow can significantly reduce time for cost estimating and eliminate human errors and mistakes. As illustrated by the application example, the proposed system can successfully address the limitations of current cost estimating practices and systems. Yet, the proposed system can be improved and extended in many aspects. For example, it can be combined with a decision support system for selecting the optimal building design or controlling construction costs during construction.

\section{Acknowledgment}

The authors are very grateful to the ASEAN University Network/Southeast Asia Engineering Education Development Network (AUN/SEED-Net) and Department of Civil Engineering, Faculty of Engineering, Chulalongkorn University for their financial support to this research project.

\section{References}

[1] A. Olanrewaju, and P.J. Anahve, "Duties and responsibilities of quantity surveyors in the procurement of building services engineering," In: M. Hajdu, and M.J. Skibniewski, eds., Creative Construction Conference 2015, Elsevier Ltd., Krakow, Poland, pp. 352-360, 2015.

[2] L. Holm, Construction Cost Estimating: Process and Practices, Prentice Hall, University of Washington, United States, 2005.

[3] A. Jrade, and S. Alkass, "Computer-integrated system for estimating the costs of building projects," Journal of Architectural Engineering, Vol. 13, No. 4, pp. 205-223, 2007.

[4] D. Kehily, and J. Underwood, "Embedding life cycle costing in 5D BIM," Journal of Information Technology in Construction, Vol. 22, pp. 145-167, 2017.

[5] S. Azhar, M. Khalfan, and T. Maqsood, "Building information modelling (BIM): Now and beyond," Construction Economics and Building, Vol. 12, No. 4, pp. 15-28, 2012.

[6] McGraw Hill Construction, The Business Value of BIM for Construction in Major Global Markets: How Contractors around the World Are Driving Innovation with Building Information Modeling SmartMarket Report, Bedford, Massachusetts, United States, 2013. 
[7] M.C. Herr, and T. Fischer, "BIM adoption across the Chinese AEC industries: An extended BIM adoption model," Journal of Computational Design and Engineering, Vol. 6, No. 2, pp. 173-178, 2019.

[8] S. Paul, "BIM Adoption around the World: How Good Are We? Geospatial World" (n.d.) [Online]. Available: https://www.geospatialworld.net/article/bim-adoptionaround-the-world-how-good-arewe.pdf [Accessed: December 2018]

[9] L. Sabol, "Challenges in cost estimating with building information modeling," IFMA World Workplace, pp. 1-16, 2008.

[10] A. Malleson, NBS International BIM Report 2016 [Online]. Available: https://www.thenbs.com/knowledge/nbs-international-bim-report-2016.pdf, [Accessed: October 2016]

[11] T. Koppinen, and N. Morrin, "Green BIM Innovation at Skanska" (n.d.) [Online]. Available: https://group.skanska.com/4a2286/siteassets/sustainability/green/ourjourney-to-deep-green/how-we-define-green/greenbiminnovation.pdf, [Accessed: December 2017]

[12] D. Goucher, and N. Thurairajah, "Advantages and challenges of using BIM: A cost consultant's perspective," Paper presented at The 49th ASC Annual International Conference, California Polytechnic State University (Cal Poly), San Luis Obispo, California, 2012.

[13] L. Sabol, "Building Information Modeling and Facility Management" (n.d.) [Online]. Available: https://onlinelibrary.wiley.com/doi/abs/10.1002/9781119572626.ch2.pdf, [Accessed: December 2017]

[14] Z. Shen, R.R. Issa, and L. Gu, "Quantitative evaluation of the BIM-assisted construction detailed cost estimates," Journal of Information Technology in Construction, Vol. 15, pp. 234-257, 2010.

[15] D.L. Mitchell, "Creating cost certainty and better buildings," Paper presented at the RICS Cobra Conference, Las Vegas, Nevada, September 2012.

[16] K. Zima, Comparative Analysis of Creating Traditional Quantity Takeoff Method and Using a BIM Tool, Report of Construction Maeconomics Conference, Prague, 2014.

[17] K. Zima, "Impact of information included in the BIM on preparation of bill of quantities," Procedia Engineering, Vol. 208, pp. 203-210, 2017.

[18] F. Abanda, and L. Byers, "An investigation of the impact of building orientation on energy consumption in a domestic building using emerging BIM (Building Information Modelling)," Energy Journal, Vol. 97, pp. 517-527, 2016.

[19] National Building Information Modeling Standard, Part 1: Overview, Principles, and Methodologies, Transforming the Building Supply Chain Through Open and Interoperable Information Exchanges (Version 1), National Institute of Building Sciences, Washington, United States, 2007.

[20] L. Brigdes, UK Government Construction Strategy: 2016 - 2020 [Online]. Available: https://assest.publishingservice.gov.uk/, [Accessed: August 2017]

[21] M. Muzvimwe, "5D BIM Explained," 2011 [Online]. Available: http://www.fgould.com/uk/articles/5d-bim-explained/. [Accessed: September 2018]

[22] S. Bennett, K. Maton, and L. Kervin, "The digital natives debate: A critical review of the evidence," British Journal of Educational Technology, Vol. 39, No. 5, pp. 775-786, 2008.

[23] P.B. Norwich, NRM2-RICS New Rules of Measurement: Detailed Measurement for Building Works, Royal Institution of Chartered Surveyors, Westwood Business Park, United Kingdom, 2012 [Online]. Available: https://www.rics.org/globalassets/ricswebsite/media/upholding-professional-standards/sector-standards/construction/nrm2-detailed-measurement-for-building-works-1st-edition-rics.pdf [Accessed: 2017] 
[24] P.B. Norwich, NRM1-RICS New Rules of Measurement: Order of Cost Estimating and Cost Planning for Capital Building Works, Royal Institution of Chartered Surveyors, United Kingdom, 2012 [Online], Available: https://www.rics.org/globalassets/ricswebsite/media/upholding-professional-standards/sector-standards/construction/nrm1-order-of-cost-estimating-and-cost-planning-2nd-edition-rics.pdf, [Accessed: 2012].

[25] Architectural Services Department, Standard Method of Measurement for Building Elements, Government of Hong Kong, Queenway, Hong Kong, 2015 [Online]. Available: https://www.archsd.gov.hk/media/171736/asdsmmbe_2015.pdf, [Accessed: January 2018]

[26] P. Smith, "BIM \& the 5D project cost manager," Procedia-Social and Behavioral Sciences, Vol 119, No. 19, pp. 475-484, 2014.

[27] H. Liu, M. Lu, and M. Al-Hussein, "BIM-based integrated framework for detailed cost estimation and schedule planning of construction projects," In: Proceedings of the International Symposium on Automation and Robotics in Construction, Sydney, Australia, Vol. 4, No. 6, pp. 286-294, 2014.

[28] Z. Ma, Z. Wei, and X. Zhang, "Semi-automatic and specification-compliant cost estimation for tendering of building projects based on IFC data of design model," Automation in Construction, Vol. 30, pp. 126-135, 2013.

[29] V. Likhitruangsilp, H.T.T. Le, N. Yabuki, and P.G. Ioannou, "A relational database management system for life-cycle cost analysis of BIM projects," In: Proceedings of EURO MED SEC 3 - Holistic Overview of Structural Design and Construction, Limassol, Cyprus, Vol. 7(1), pp. 1-6, 2020.

[30] V. Likhitruangsilp, H.T.T. Le, N. Yabuki, and P.G. Ioannou, "An Integrated System For Building Life-Cycle Cost Analysis," Paper presented at The Interdependence between Structural Engineering and Construction Management, United States, 2019.

[31] RIB Group, CostX 6.6, 2017. Retrieved from https://www.exactal.com/en/costx/bim/

[32] Innovaya Company, Innovaya Visual Estimating, 2013. Retrieved from http://www.innovaya.com/prod_ve.htm.

[33] Trimble General Contractor Solutions, Vico Office for Cost, 2018. Retrieved from https://gc.trimble.com/product-categories/vico-office-cost

[34] B. Hardin, and D. McCool, BIM and Construction Management: Proven Tools, Methods, and Workflows, $2^{\text {nd }}$ Edition, John Wiley and Sons, United States, 2015.

[35] H. Jaakkola, and B. Thalheim, "Architecture-Driven Modelling Methodologies," Paper presented at The $20^{\text {th }}$ European-Japanese Conference on Information Modelling and Knowledge Bases, EJC 2010, Finland, pp. 97-116, 2010.

[36] R.S. Means, Assemblies Costs with RSMeans Data (43 ${ }^{\text {rd }}$ Annual Edition), Kingston, Massachusetts, United States, 2018.

[37] H.T.T. Le, A BIM-Database-Integrated System for Evaluating Building Life-Cycle Costs Using a Multi-Parametric Model, Thesis (PhD), Chulalongkorn University, Faculty of Engineering, Thailand, 2019.

[38] H.T.T. Le, V. Likhitruangsilp, and N. Yabuki, "A BIM-integrated relational database management system for evaluating building life-cycle costs," Engineering Journal, Vol. 21, No. 2, pp. 75-86, 2020. 